\title{
Exhaled breath condensate biomarkers
} in COPD

\author{
Z.L. Borrill, K. Roy and D. Singh
}

ABSTRACT: Biomarkers in chronic obstructive pulmonary disease may be useful in aiding diagnosis, defining specific phenotypes of disease, monitoring exacerbations and evaluating the effects of drugs. Exhaled breath condensate is a noninvasive means of sampling the airways, allowing biomarkers of airway inflammation and oxidative stress to be measured. In the present review, the use of exhaled breath condensate biomarkers in chronic obstructive pulmonary disease is explored and potential applications in diagnosis, disease phenotyping, exacerbation monitoring and clinical trials are considered. Exhaled breath condensate biomarkers are comprehensively reviewed in terms of method validation, reproducibility, disease specificity and sensitivity to detect changes in airway inflammation.

The commonly used exhaled breath condensate methodologies in chronic obstructive pulmonary disease patients are shown to have considerable variability, due to technical issues concerning both sample collection and analysis. Despite these issues, there is still data to support the use of exhaled breath condensate biomarkers for monitoring chronic obstructive pulmonary disease exacerbations and the response to pharmacological intervention. Further improvements to sample collection and analysis methods will improve the sensitivity of these biomarkers. The use of cytokine arrays, mass spectrometry and nuclear magnetic resonance profiling of exhaled breath condensate has opened a new avenue for analysis, as hypothesis generation from such profiling may lead to further selection of biomarkers for specific analysis.

KEYWORDS: Biomarker, chronic obstructive pulmonary disease, clinical trials, exhaled breath condensate, methodology

hronic obstructive pulmonary disease (COPD) is characterised by airway inflammation and progressive airflow limitation. Despite major advances in the symptomatic control of this disease, there is currently a lack of drugs that halt disease progression. There is a pressing need to develop drugs to modify the chronic inflammatory processes involved in this common disease and several classes of drug, with novel mechanisms of action, are now in clinical development. Validated methods are needed in order to assess short- and long-term efficacy of these new drugs.

There is currently a reliance on forced expiratory volume in one second (FEV1) to measure therapeutic effects in COPD clinical trials. While this may be appropriate for bronchodilators, the effects of anti-inflammatory drugs on pulmonary function may have a slow onset and so require long-term studies. Such studies are expensive and there may be safety issues during long-term exposure to drugs whose side-effects are not well understood. Shorter studies focusing on "proof of pharmacology" can show that the drug has the desired pharmacological action and can provide the confidence to perform larger studies. These studies need validated biomarkers in order to detect pharmacological actions. Such biomarkers should be related to the disease process, so that there is a possibility that a change in the biomarker may indicate a therapeutic benefit.

COPD is a heterogeneous disease and there is much interest in the use of biomarkers that can define specific disease subgroups with different long-term prognoses or responses to therapeutic intervention. Candidate biomarkers include sputum neutrophilia, which is predictive of decline in lung function [1] and sputum eosinophilia, which is predictive of response to corticosteroid therapy $[2,3]$. Other uses of biomarkers may be to aid in the diagnosis of COPD or to monitor exacerbations [4].

\section{AFFILIATIONS}

Medicines Evaluation Unit, Langley Building, The University of Manchester, Wythenshawe Hospital, Manchester, UK.

\section{CORRESPONDENCE}

Z.L. Borrill

Medicines Evaluation Unit

Langley Building

The University of Manchester

Wythenshawe Hospital

Southmoor Rd

Manchester

M23 9QZ

UK

Fax: 441619461459

E-mail: zborril@meu.org.uk

Received:

September 042007

Accepted after revision:

February 132008

STATEMENT OF INTEREST

None declared. 
Exhaled breath condensate (EBC) is a noninvasive method of sampling the airways that can be repeated easily and is acceptable to patients. The use of EBC to monitor airway inflammation is based on the hypothesis that it contains aerosolised particles from the airway lining fluid (ALF). These aerosolised particles are generated from the entire respiratory tract (from mouth to alveolus) into air which is saturated with water vapour. As the expired air is cooled, this water vapour condenses around the aerosolised particles forming EBC. This process therefore traps nonvolatile substances contained within the ALF, such as proteins and water-soluble volatile substances. EBC is being increasingly used in respiratory medicine to measure biomarkers of airway inflammation and oxidative stress, and guidelines for its use have recently been published by a European Respiratory Society Task Force [5].

In the present review, the potential of EBC measurements to be used as biomarkers in COPD are reported. The ideal characteristics of a pulmonary biomarker in COPD are that it is: 1) reproducible; 2) disease specific, as it is related to the underlying pathophysiology of the disease; and 3) sensitive enough to detect changes in airway inflammation caused by exacerbations or therapeutic intervention. In this context, first the important methodological issues concerning EBC measurements in COPD that could influence reproducibility are reviewed, including: collection and storage; analytical techniques; variation of EBC biomarkers over time; and other factors affecting EBC composition, such as smoking and demographics. Secondly, a comprehensive evaluation of each current EBC biomarker is presented, focussing on potential applications in: 1) diagnosis; 2) disease stratification and phenotyping; 3) exacerbation monitoring; and 4) clinical trials of anti-inflammatory drugs. Finally, estimations of the number of subjects required in clinical trials of therapeutic interventions using EBC mediators as outcome measures are provided. Accordingly, the present review is structured in two main sections: first, methodological issues; and secondly, the use of EBC biomarkers in COPD. The review concludes with a critical summary of the existing data in COPD.

\section{SEARCH STRATEGY}

The present authors conducted a Medline search using the terms "exhaled breath condensate" or "expired breath condensate". All references from the recent comprehensive EBC review [5] were also considered. All papers including EBC collected from subjects with COPD were included. Throughout the present review, papers from healthy subjects or patients with other respiratory diseases were used to provide supporting information, but the critical analysis of the potential of specific EBC biomarkers in COPD patients for diagnosis, phenotyping, exacerbation monitoring and in clinical trials is centred on published data from COPD patients. Papers using EBC collected from healthy subjects or subjects with respiratory diseases other than COPD were also included to provide supporting information if they contained relevant data related to methodological issues of EBC collection or analysis.

\section{EBC COLLECTION}

\section{Collection device}

Several different devices have been used to collect EBC. The commercially available EcoScreen (Jaeger, Wurzburg, Germany) and R-tubes (Respiratory Research Inc., Charlottesville, VA, USA) are commonly used, while some laboratories have used their own custom-made devices. Studies comparing collection devices have shown that there may be differences; in a mixed group of patients with asthma or allergic rhinitis and healthy volunteers, significantly higher $\mathrm{pH}$ levels were observed in EBC collected using EcoScreen compared to R-tubes [6]. Significantly higher eotaxin and cysteinyl-leukotriene levels have also been observed using the EcoScreen compared to R-tubes [7]. In contrast, studies including only healthy subjects have demonstrated no significant difference in the $\mathrm{pH}$ of EBC between the EcoScreen and R-tubes $[7,8]$ and no difference in aldehyde concentrations comparing the EcoScreen with a custom-made device [9]. The possible differences between devices appear to vary with the biomarker measured and with the presence of disease.

The condenser coating used can influence the measurements obtained, due to the adhesive and electrical properties of the condensation equipment. Each EBC biomarker has specific physical and chemical properties resulting in a unique interaction with each condenser system. RosiAs et al. [10] compared EBC collected using condensers with five different coatings and the EcoScreen in healthy volunteers. Use of condensers coated with silicone and glass resulted in significantly higher detection of 8-isoprostane and albumin than other coatings (Teflon, aluminium, polypropylene and EcoScreen). Measurement of nitrates $\left(\mathrm{NO}_{2}^{-}\right)$/nitrites $\left(\mathrm{NO}_{3}{ }^{-}\right)$in EBC may also be affected by contamination of the sample from plastic and glass surfaces [11].

VAUGHAN et al. [12] observed that using the R-tube at different temperatures of collection had no effect on the $\mathrm{pH}$ of EBC in healthy subjects. This effect has not been investigated with the use of other devices, nor in COPD patients.

The different EBC collection devices in use have been well tolerated and found to be safe. While no formal safety studies have been performed in COPD patients, there have been no adverse effects reported in studies in which EBC has been successfully collected from patients with unstable and severe COPD [13, 14]. Transmission of infection between subjects using nondisposable EBC collection systems is theoretically possible, although bacterial DNA cross-contamination was not observed in a study of EBC taken from patients with cystic fibrosis (CF) [15]. Exhalation particle filters are not recommended as they may trap molecules in the expired air [5]. Use of a one-way valve or disposable collection devices limits the infection risk.

\section{Pattern of breathing}

The volume of EBC obtained increases with higher minute ventilation and/or tidal volume [12,16-18]. This may simply reflect the increase in volume of air exhaled or be due to greater turbulence generating increased aerosolisation of ALF. Studies of EBC composition in COPD have not measured expiratory flow rates. However, disease severity in COPD patients affects expiratory flow rate, which may alter the concentration of biomarker. EBC hydrogen peroxide $\left(\mathrm{H}_{2} \mathrm{O}_{2}\right)$ concentration is inversely proportional to the expiratory flow rate during collection in asthma patients and healthy subjects using resistors to generate flow rates of 140,69 and $48 \mathrm{~mL} \cdot \mathrm{s}^{-1}$ [17]. In contrast, the pattern of breathing has no significant effect on concentrations of leukotriene $(\mathrm{LT}) \mathrm{B}_{4}, \mathrm{LTE}_{4}$, 
prostaglandin $(\mathrm{PG}) \mathrm{E}_{2}[16]$, aldehydes [9], $\mathrm{pH}[12,18], \mathrm{NO}_{3}{ }^{-}$or total protein [18]. The effect of breathing pattern is therefore dependent on the specific mediator examined. The effect of different breathing patterns on the concentration of EBC mediators should be investigated in COPD patients of different severities.

\section{Nasal contamination}

During exhaled nitric oxide (NO) measurement, nasal contamination is minimised by expiratory flow resistance, which ensures nasopharyngeal velum closure. The use of a resistor has also lead to more reproducible $\mathrm{EBC} \mathrm{NO}_{3}{ }^{-}$concentrations [19]. However, its use requires increased effort and does not prevent inspiratory nasal contamination. Contamination of EBC samples with nasal air is probably unavoidable in COPD patients.

The use of a nose peg opens the nasopharyngeal velum, resulting in nasal contamination of the exhaled air. In a study of $\mathrm{pH}$ of EBC in COPD patients and healthy subjects, similar variability between samples separated by $1 \mathrm{~h}$ without a nose peg, to that observed comparing collection with or without a nose peg was observed [20]. This suggests that any effect of nose peg use is no greater than the natural changes in airway $\mathrm{pH}$ over time. The effect of nose peg use on the contribution of the nasal airway to other specific EBC constituents in COPD is largely unknown and requires further study.

Most EBC studies have used oral inhalation and exhalation during collection of EBC. One study in healthy subjects and patients with allergic rhinitis observed a significantly higher volume of EBC during oral compared with nasal inhalation, but no difference in levels of adenosine, ammonia and thromboxane (TX)B $\mathrm{B}_{2}$ [21].

\section{Oral contamination}

Studies comparing matched EBC samples obtained orally and from endotracheal or tracheostomy tubes found no difference in levels of $\mathrm{pH}$, adenosine or $\mathrm{TXB}_{2}[12,21]$. However, higher concentrations of ammonia have been observed in EBC samples collected orally, suggesting that ammonia in EBC is mainly derived from the upper airways and oropharynx [21, 22]. It has been argued that the $\mathrm{pH}$ of orally collected $\mathrm{EBC}$ is mainly driven by this high ammonia content [23]. However, subsequent data has shown that the $\mathrm{pH}$ of $\mathrm{EBC}$ is not significantly affected by oral ammonia [24]. Furthermore, the markedly higher variability in $\mathrm{pH}$ of EBC observed in COPD patients compared with healthy subjects [20] is more likely to be due to differences in airway $\mathrm{pH}$ between the groups than the degree of oral contamination with ammonia. Further support for the lack of contribution of mouth contamination to EBC measurements comes from the report of no relationship between the $\mathrm{pH}$ in saliva and $\mathrm{EBC}$, in healthy subjects [12].

Oral contamination may also affect EBC NO metabolites, as nitrogen-rich meals were shown to boost levels of $\mathrm{NO}_{2}^{-}$and $\mathrm{NO}_{3}{ }^{-}$in healthy subjects [25]. A recent study of healthy subjects observed high levels of $\mathrm{LTB}_{4}$ in saliva. $\mathrm{LTB}_{4}$ levels were also raised in EBC samples that contained salivary amylase [26]. The authors concluded that salivary contamination is a likely source of $\mathrm{LTB}_{4}$ detected in EBC. This is in contrast to previous studies, which have found salivary amylase to be undetectable in EBC samples $[9,16,19,27,28]$. However, it has been argued that the analytical methods used may not have been sensitive enough to definitively exclude salivary contamination. The possible effect of oral contamination probably cannot be ignored if high levels of a specific mediator are present in saliva. Therefore, the contribution of oral contamination should be investigated with respect to each specific EBC mediator. In conclusion, the effects of oral contamination, pattern of breathing and the condenser device used must be standardised separately for each specific EBC mediator and in different diseases (table 1).

\section{Concentration artefact}

It can be hypothesised that any decrease in EBC solute concentration could be due to a corresponding decrease in ALF concentration or the presence of fewer aerosolised

\section{TABLE 1 Mediator-specific methodological issues in exhaled breath condensate collection}

\begin{tabular}{|c|c|c|c|}
\hline Mediator & Pattern of breathing & Oral contamination & Condenser coating \\
\hline pH & No effect [12] & No effect [12] & $\begin{array}{c}\text { EcoScreen }>\text { R-tube in asthma/allergic rhinitis/healthy } \\
\qquad 6] \\
\text { R-tube }=\text { EcoScreen in healthy }[7,8]\end{array}$ \\
\hline LTB $_{4}$ & No effect [16] & Salivary contamination [26] & \\
\hline Cysteinyl-LTs & No effect [16] & & EcoScreen > R-tube [7] \\
\hline 8-isoprostane & & & Silicone/glass highest concentrations [10] \\
\hline Nitrate/nitrite & No effect [18] & Increased by oral nitrate load [25] & \\
\hline Protein & No effect [18] & & \\
\hline Albumin & & & Silicone/Glass highest concentrations [10] \\
\hline Aldehydes & No effect [9] & & R-tube $=$ other device $[9]$ \\
\hline
\end{tabular}

LT: leukotrine; PG: prostaglandin; $\mathrm{H}_{2} \mathrm{O}_{2}$ : hydrogen peroxide. EcoScreen is manufactured by Jaeger, Wurzburg, Germany; R-tube: Respiratory Research Inc., Charlottesville, VA, USA. 
particles of ALF in the same volume of EBC (i.e. a dilutional effect). Attempts have been made to standardise EBC by using urea [29], protein [30], electrolytes [29, 31] or conductance of lyophilised samples [31]. Whereas the ratio of aerosolised particles of ALF to water vapour may vary, the concentration of a dilution factor in EBC would enable calculation of the true concentration of a mediator in the ALF. However, for such calculations to be valid, the dilution factor must be of known concentration in serum, diffuse through cell membranes at a constant rate and not be produced in the airways themselves. So far, none of these methods has been validated and further research is required before such calculations can be made with accuracy. Such a dilution control factor would be particularly useful in COPD studies where between- and within-subject variability may be high, but it remains to be seen whether such methods can improve EBC reproducibility. An alternative strategy that may bypass errors caused by dilutional effects is to measure ratios between mediators. This approach has been used in induced sputum supernatant, i.e. measuring the ratio between matrix metalloproteinases and their inhibitors [32].

\section{Storage}

For practical reasons, EBC is usually frozen to be analysed later. However there are only limited reports of the effect of freezing on the composition of EBC. In analysing the $\mathrm{pH}$ of EBC using argon de-aeration to provide gas standardisation of the carbon dioxide $\left(\mathrm{CO}_{2}\right)$ concentration in the sample, it has been shown that samples from healthy subjects frozen at $-20^{\circ} \mathrm{C}$ for $>1$ yr [12] and from COPD patients at $-80^{\circ} \mathrm{C}$ for $\leqslant 3$ months [20] are stable. However, it has recently been shown that $\mathrm{pH}$ values obtained without gas standardisation after freezing EBC for 8 weeks were significantly higher than those obtained immediately after analysis [6]. This may be due to the loss of $\mathrm{CO}_{2}$ from the sample, so the effect of freezing on other volatile substances should be investigated.

Other studies have shown no effect on 8-isoprostane [27], $\mathrm{NO}_{2}{ }^{-} / \mathrm{NO}_{3}{ }^{-}$[33], $\mathrm{H}_{2} \mathrm{O}_{2}$ [34], interleukin (IL)- $1 \beta$ or tumour necrosis factor (TNF)- $\alpha$ levels [35] in EBC after freezing for periods varying from 3 weeks to 2 months. In conclusion, it is likely that freezing samples has little effect on EBC composition, with the exception of $\mathrm{pH}$ without gas standardisation.

\section{EBC ANALYSIS}

\section{Gas standardisation}

De-aeration of EBC samples using argon, otherwise referred to as gas standardisation, is commonly performed prior to $\mathrm{pH}$ measurement $[12,36,37]$. This process causes a decrease in $\mathrm{CO}_{2}$ levels, which increases $\mathrm{pH}[38]$ and improves $\mathrm{pH}$ of EBC reproducibility [12]. The $\mathrm{pH}$ has also been measured without gas standardisation, as it has been argued that the concentration of $\mathrm{CO}_{2}$ in the sample is important in itself $[18,39]$. However, non-de-aerated samples have unstable $\mathrm{pH}$ due to rapid interaction of the sample with ambient air and resulting change in $\mathrm{CO}_{2}$ concentration, making sample-analysis time crucial [40]. The mean change in $\mathrm{pH}$ after gas standardisation is $\sim 1[20,40,41]$. However, whereas the effect of gas standardisation on samples with a $\mathrm{pH}>6$ is predictable, it causes unpredictable $\mathrm{pH}$ changes in samples with $\mathrm{pH}<6[12$, 40, 42]. Acidic EBC samples that change little after gas standardisation may contain a low concentration of $\mathrm{CO}_{2}$, but high concentrations of other acids.

The process of gas standardisation causes an incomplete and variable reduction in $\mathrm{CO}_{2}$ levels over time [38]. An alternative method to overcome this issue is $\mathrm{CO}_{2}$ standardisation by bubbling $\mathrm{CO}_{2}$ through EBC samples, which improves the reproducibility of EBC $\mathrm{pH}$. Further studies are needed to assess the applicability of this method.

\section{Immunoassays}

ELISA is a common method for measuring inflammatory mediators in EBC. It is easy to perform, relatively inexpensive and studies have reported good intra-assay reproducibility [14, 43]. However, despite the use of identical ELISA kits in similar patient groups, the levels of biomarkers quoted between different studies have varied considerably. For example, the mean values of $\mathrm{LTB}_{4}$ in COPD have varied 10-fold [13, 43]. The specificities of the $\mathrm{LTB}_{4}$ ELISA and the 8-isoprostane radioimmunoassay have been confirmed using reverse-phase highperformance liquid chromatography (HPLC) [44, 45]. However, the authors themselves conclude that further validation using mass spectrometry (MS) would provide more definitive quantitative analysis of the presence of these compounds in EBC.

It is probable that the sensitivity of the ELISA technique is inadequate for the measurement of some EBC mediators, as studies have reported individual levels below the limit of detection of the assay $[13,16]$. This suggests that the authors either diluted the standard below the recommended level or that they extrapolated the standard curve below the lowest concentration of standard. These are not standard practices and may lead to a loss of accuracy. The concentration of EBC samples by lyophilisation has been used by investigators prior to mediator measurement in an attempt to improve sensitivity and reproducibility [31].

\section{Alternative analytical methods}

The combination of gas chromatography (GC) or liquid chromatography (LC) and MS offer increased sensitivity for EBC analysis. However, these techniques are more complex, expensive and time consuming than ELISAs. Nevertheless, they may be valuable for validating ELISAs or enabling more accurate determination of the composition of EBC.

Using GC-MS, CÁP et al. [46] found detectable levels of LTs $B_{4}$, $\mathrm{D}_{4}$ and $\mathrm{E}_{4}$ in all EBC samples from asthma patients and healthy subjects, suggesting that this technique may have improved sensitivity over ELISA. However, the use of arachidonic acid as the internal standard in the study may have lead to an overestimation of $\mathrm{LTB}_{4}$ concentrations. A subsequent study using LC-MS with $\mathrm{LTB}_{4}$ as the internal standard found detectable $\mathrm{LTB}_{4}$ levels only in steroid-naïve asthma patients, but not in healthy subjects or steroid-treated asthma [47]. The detection limit of the assay was $100 \mathrm{pg} \cdot \mathrm{mL}^{-1}$ (compared with ELISA which is $5 \mathrm{pg} \cdot \mathrm{mL}^{-1}$ ), suggesting that the sensitivity of the assay needs to be improved. Furthermore, quantification of the within-subject reproducibility of these techniques has yet to be described.

LC-MS has also been used to measure aldehydes in a study of COPD patients, healthy smokers and nonsmoking controls [9]. 
Malondialdehyde levels were increased in COPD patients compared with healthy smokers and in healthy smokers compared with healthy nonsmokers and other aldehydes were detectable in all subjects. The reproducibility of the measurements was assessed and reported as adequate, but the small sample sizes used may have made this conclusion unreliable. Adenosine has been measured in EBC from asthmatic patients and healthy subjects by HPLC [48]. Levels were increased in steroid-naive asthma patients compared to steroid-treated patients and healthy controls. The within-subject variability of this assay (limits of agreement) was shown to be $3.6 \mathrm{nM}$, with the majority of absolute measurements in patients ranging 5-35 $\mathrm{nM}$, indicating that the variability was low compared with the absolute measurement obtained.

One recent study has used the technique of nuclear magnetic resonance-based metabolomic analysis to profile low molecular weight metabolites in EBC [49]. Selected signals from this technique enabled more accurate differentiation between healthy children and those with asthma. This method has promise to generate hypotheses for new metabolic pathways, which may have a role in asthma, as well as identification of potential novel biomarkers.

\section{WITHIN-SUBJECT VARIATION OVER TIME}

It is important to quantify the changes in mediator concentrations observed over time ("within-subject variability") in order to determine the natural variation of EBC composition. The reports of the within-subject variability of EBC biomarkers are outlined in table 2.

The majority of these studies have reported variability as being "minimal". However, there are several reasons why the variability of EBC mediators may have been underestimated. First, use of the coefficient of variation, group mean statistics or correlation coefficients may have underestimated individual variability [57]. Such analyses provide information about overall group differences but not the potential for repeated samples from a single individual to vary over time. Studies using these methods to investigate variability may observe no significant change in mean group values over time, or report low coefficients of variation. However, this does not necessarily mean that the within-subject variability is low; the BlandAltman method can show that while some individuals have highly reproducible measurements over time, considerable variation can exist in other subjects. The limits of agreement obtained by this method provide a numerical estimation expressed in the units of the measurement, of the maximum degree of variability expected within an individual during repeated sampling [57]. Using a particular EBC biomarker to detect a significant biological change in an individual, such as after administration of a drug, would require a change greater than the limits of agreement. In contrast, coefficients of variation and correlation coefficients provide statistics using arbitrary values that do not relate to the units of the measurement being studied.

Several studies have investigated EBC mediator variability over time in healthy subjects. It is probable that within-subject variability in patients with disease will be higher due to changes in lung inflammation over time. Within-subject variability in healthy subjects was compared with COPD patients using the Bland-Altman method, and was demonstrated to have greater within-subject variability of $\mathrm{pH}$ of EBC in COPD patients over time, compared with that seen in healthy subjects [20]. Bland-Altman analysis has also been used to assess within-subject variability for EBC $\mathrm{LTB}_{4}$ and $\mathrm{H}_{2} \mathrm{O}_{2}$ (table 2). Within-subject variability of $\mathrm{LTB}_{4}$ was markedly higher in patients with disease compared with healthy subjects $[51,53,54]$, similar to the findings for $\mathrm{pH}$. In contrast, the within-subject variability of $\mathrm{EBC} \mathrm{H}_{2} \mathrm{O}_{2}$ appears to be similar in patients and healthy subjects [27, 28, 34], suggesting that the variability of this mediator is not influenced by the development of lung disease. Further studies are required in order to confirm whether within-subject variability of other EBC mediators is higher in COPD than that observed in healthy subjects.

\section{OTHER FACTORS INFLUENCING EBC COMPOSITION}

Smoking has been found to cause an acute increase in EBC 8isoprostane [58] and $\mathrm{H}_{2} \mathrm{O}_{2}$ levels [59], which may be useful biomarkers of oxidative stress in COPD. BALINT et al. [60] showed that $\mathrm{NO}$ metabolites $\left(\mathrm{NO}_{2}{ }^{-} / \mathrm{NO}_{3}{ }^{-}\right)$were significantly increased 30 mins after smoking two cigarettes and had returned to baseline at 90 mins. Conversely, levels of EBC $\mathrm{NO}_{3}{ }^{-}$alone, s-nitrosothiols and nitrotyrosine were unchanged. Other authors have observed no difference in $\mathrm{NO}_{3}{ }^{-}$, IL-1 $\beta$, TNF- $\alpha$, total protein or aldehyde levels after smoking one cigarette $[9,35]$. No studies looking at the acute effects of smoking have included a placebo group, making it possible that the above observations were simply due to variation over time. However, due to the possible acute effects of cigarette smoke on certain EBC mediators, it is recommended that subjects should refrain from smoking for $3 \mathrm{~h}$ prior to EBC collection [5].

EBC $\mathrm{H}_{2} \mathrm{O}_{2}$ concentration exhibits significant diurnal variation in COPD patients [50] and in healthy subjects [59]. The $\mathrm{pH}$ of EBC does not appear to exhibit this phenomenon in healthy subjects [12] but this has not been investigated in COPD patients. Compared with asthma, COPD is defined as having relatively low variation in airway calibre. However, the observed circadian variation in airflow [61], may affect the concentration of EBC mediators that are flow dependent. Further studies are needed in order to establish the presence of circadian rhythm of mediators in EBC from COPD patients.

In a study of healthy subjects and COPD patients it was observed that age, height and weight had no effect on EBC volume [30]. However, the concentration of $\mathrm{H}_{2} \mathrm{O}_{2}$ in $\mathrm{EBC}$ increases with advancing age [59]. In a large study of $>400$ healthy subjects, no differences in the $\mathrm{pH}$ of EBC were observed based on age, sex or race [62].

CARPAGNANO et al. [63] observed a significant increase in EBC IL- 6 and TNF- $\alpha$ and a reduction in $\mathrm{pH}$ after sputum induction with hypertonic compared with isotonic saline solution. ANTCZAK et al. [64] observed an increase in both $\mathrm{LTB}_{4}$ and 8isoprostane levels in EBC collected following sputum induction in healthy subjects, which was not observed in asthma patients. These observations have implications for the order in which tests are performed during clinical trials, with EBC perhaps best performed before induced sputum. 
TABLE 2 Exhaled breath condensate (EBC) biomarker variability

\begin{tabular}{|c|c|c|c|c|}
\hline First author [ref.] & EBC mediator & Subjects & Statistical method & Variability \\
\hline VAUGhan [12] & $\mathrm{pH}$ & HNS $n=76$ & CV & BD $4.5 \%$ \\
\hline \multirow[t]{4}{*}{ BORRILL [20] } & $\mathrm{pH}$ & HNS $n=12$ & LA & WD $0.03(-0.33-0.4)$ \\
\hline & & & & BD $-0.02(-0.46--0.44)$ \\
\hline & & COPD $n=15$ & & WD $0.49(-1.5-2.48)$ \\
\hline & & & & BD $-0.25(-2.5-3.0)$ \\
\hline \multirow[t]{4}{*}{ LeUNG [8] } & $\mathrm{pH}$ & HNS $n=9$ & CV & $\mathrm{BD} 2.7 \% \mathrm{RT} 4.1 \% \mathrm{ES}$ \\
\hline & 8-isoprostane & & & BD 12.4\% RT 9.7\% ES \\
\hline & Cys-LTs & & & BD $14.2 \%$ RT $19.6 \%$ ES \\
\hline & $\mathrm{LTB}_{4}$ & & & BD $25.4 \%$ RT $24.1 \%$ ES \\
\hline VAN BEURDen [34] & $\mathrm{H}_{2} \mathrm{O}_{2}$ & COPD $n=20$ & LA & WD $-0.01(-0.19-0.17) \mu \mathrm{mol} \cdot \mathrm{L}^{-1}$ \\
\hline KostIKAS [27] & $\mathrm{H}_{2} \mathrm{O}_{2}$ & $\mathrm{COPD} / \mathrm{HS} \mathrm{n}=17$ & LA & BD $0.08(-0.02-0.18) \mu \mathrm{mol} \cdot \mathrm{L}^{-1}$ \\
\hline \multirow[t]{2}{*}{ VAN BEURDEN [50] } & $\mathrm{H}_{2} \mathrm{O}_{2}$ & COPD $n=20$ & $\mathrm{CV}$ & BD $45 \%$ \\
\hline & & $\mathrm{HS} n=20$ & & BD $43 \%$ \\
\hline LOUKIDES [28] & $\mathrm{H}_{2} \mathrm{O}_{2}$ & HNS $n=5$ & LA & $\mathrm{BD} 0.07(-0.07-0.21) \mu \mathrm{mol} \cdot \mathrm{L}^{-1}$ \\
\hline KostIKAs [27] & 8-isoprostane & $\mathrm{COPD} / \mathrm{HS} \mathrm{n}=17$ & LA & BD $13(5-21) \mathrm{pg} \cdot \mathrm{mL}^{-1}$ \\
\hline \multirow[t]{4}{*}{ BORRILL [51] } & 8-isoprostane & COPD $n=24$ & LA & WD -2.2 (-51.6-47.2) pg.mL $\mathrm{mL}^{-1}$ \\
\hline & & & & $\mathrm{BD} 7.1(-61.4-75.7) \mathrm{pg} \cdot \mathrm{mL}^{-1}$ \\
\hline & $\mathrm{LTB}_{4}$ & & & WD $-0.2(-31.8-31.4) \mathrm{pg} \cdot \mathrm{mL}^{-1}$ \\
\hline & & & & BD $4.7(-29.3-38.6) \mathrm{pg} \cdot \mathrm{mL}^{-1}$ \\
\hline CoRRADI [9] & Aldehydes & COPD $n=8$ & $\mathrm{CV}$ & BD $8.2-14.3 \%$ \\
\hline BALINT [52] & NT & HNS $n=7$ & CV & $\mathrm{BD} 6 \%$ \\
\hline GanAS [33] & NOx & HNS $n=5$ & LA & BD $0.03(-0.01-0.07) \mu \mathrm{M}$ \\
\hline \multirow[t]{2}{*}{ Carpagnano [53] } & $\mathrm{LTB}_{4}$ & HNS $n=10$ & LA & $\mathrm{BD}-0.04(-0.14-0.22) \mathrm{pg} \cdot \mathrm{mL}^{-1}$ \\
\hline & IL-6 & & & BD $0.03(-0.21-0.27) \mathrm{pg} \cdot \mathrm{mL}^{-1}$ \\
\hline KostIKAS [54] & $\mathrm{LTB}_{4}$ & Mixed $n=13$ & LA & BD -0.56 (-8.74-9.86) pg.mL ${ }^{-1}$ \\
\hline \multirow[t]{2}{*}{ Carpagnano [55] } & IL-4 & HNS $n=10$ & $\mathrm{CV}$ & $4.2 \%$ \\
\hline & IL-6 & & & $5.9 \%$ \\
\hline KostiKas [56] & $\mathrm{PGE}_{2}$ & HNS/asthma $n=30$ & ICC & BD 0.79 \\
\hline MontusChI [43] & $\mathrm{PGE}_{2}$ & COPD $n=25$ & ICC & BD 0.82 \\
\hline
\end{tabular}

HNS: healthy nonsmoker; CV: coefficient of variation; BD: between-day variability; LA: mean difference with limits of agreement; WD: within-day variability; COPD: chronic obstructive pulmonary disease; RT: R-Tube (Respiratory Research Inc., Charlottesville, VA, USA); ES: EcoScreen (Jaeger; Wurzburg, Germany); Cys-LT: cystenylleukotriene; LT: leukotriene; $\mathrm{H}_{2} \mathrm{O}_{2}$ : hydrogen peroxide; HS: healthy smoker; NT: nitrotyrosine; NOx: nitrogen oxides; IL: interleukin; PG: prostaglandin; ICC: intraclass correlation coefficient.

\section{USE OF EBC BIOMARKERS IN COPD}

The potential of specific EBC biomarkers in COPD will now be considered systematically with respect to the following aspects. 1) Diagnosis. The ability of biomarkers to differentiate between health and disease and display specificity for COPD. 2) The ability of biomarkers to distinguish different severities and phenotypes of COPD. 3) The ability of biomarkers to monitor exacerbations of COPD. 4) The ability of biomarkers to monitor the effect of therapeutic interventions in COPD.

This part of the review uses subheadings (Diagnosis, Phenotyping, Exacerbations and Clinical trials) in order to critically and systematically appraise each of these points in turn. Where no subheading is presented, there is no published data in COPD or other patient groups concerning this area. The evidence for the potential of EBC biomarkers in COPD phenotyping, exacerbation monitoring and clinical trials is summarised in table 3, while healthy controls are included in diagnosis by necessity.

\section{pH}

Airway acidification and its regulation are thought to be implicated in the pathogenesis of obstructive lung disease [74]. One potential mechanism is that protons cause the release of tachykinins, leading to bronchoconstriction and airway inflammation. Unlike other EBC mediators for which reported levels in similar subject groups may vary widely, the mean EBC $\mathrm{pH}$ observed in healthy subjects from different studies is similar. This "normal range" has been confirmed in a study of $>400$ healthy subjects where the median $\mathrm{pH}$ was 8.0 [62]. This important observation suggests that the $\mathrm{pH}$ of EBC is a reproducible measurement across different laboratories.

\section{Diagnosis}

Using EBC, studies have shown that patients with COPD [20, 37], acute and stable asthma [36, 75], bronchiectasis [37], chronic cough [41], CF [75] and patients on ventilators [42] have airway acidification. Figure 1 summarises previous 


\begin{tabular}{|c|c|c|c|c|}
\hline TABLE 3 & \multicolumn{4}{|c|}{$\begin{array}{l}\text { Summary of the data available in chronic obstructive pulmonary disease (COPD) patients for each exhaled breath } \\
\text { condensate (EBC) biomarker with respect to diagnosis, disease severity/phenotype, monitoring of exacerbations and } \\
\text { therapeutic intervention }\end{array}$} \\
\hline pH & $\begin{array}{l}\mathrm{pH} \text { reduced in } \\
\text { COPD }[20,37]\end{array}$ & $\begin{array}{l}\text { pH correlates with sputum neutrophilia [37] } \\
\text { pH correlates with FEV1 [37] } \\
\text { or has no correlation with FEV1 [20] }\end{array}$ & No data & No data \\
\hline $\mathrm{PGE}_{2}$ & $\begin{array}{l}\mathrm{PGE}_{2} \text { increased in } \\
\text { COPD [43] }\end{array}$ & No data & No data & $\begin{array}{l}\text { Reduced } \mathrm{PGE}_{2} \\
\text { with ibuprofen [65] }\end{array}$ \\
\hline Cytokines & $\begin{array}{c}\text { IL-6, TNF- } \alpha \text { and IL-10 are } \\
\text { increased in COPD }[63,66]\end{array}$ & $\begin{array}{l}\text { IL-6 correlates with smoking } \\
\text { history and FEV1 [66] }\end{array}$ & $\begin{array}{c}\text { Increased levels (multiplex array) } \\
\text { during exacerbations [67] }\end{array}$ & No data \\
\hline 8-isoprostane & $\begin{array}{l}\text { 8-isoprostane increased in } \\
\text { COPD }[27,58,73]\end{array}$ & $\begin{array}{l}\text { No correlation with smoking, sputum } \\
\text { cells or dyspnoea score [27, 58]; 8-isoprostane } \\
\text { increased in severe COPD [73] }\end{array}$ & $\begin{array}{l}\text { Increased 8-isoprostane } \\
\text { during exacerbations [13] }\end{array}$ & No data \\
\hline NO metabolites & $\begin{array}{c}\mathrm{NO}_{2}{ }^{-} \text {and RS-NO } \\
\text { increased in COPD [73] }\end{array}$ & No data & No data & No data \\
\hline
\end{tabular}

FEV1: forced expiratory volume in one second; LT: leukotriene; PG: prostaglandin; IL: interleukin; TNF: tumour necrosis factor; $\mathrm{H}_{2} \mathrm{O}_{2}$ : hydrogen peroxide; $\mathrm{NO}_{2}{ }^{-}$: nitrite; $\mathrm{RS}^{-}$ NO: nitrosothiols; NO: nitric oxide.

studies of EBC $\mathrm{pH}$, showing marked overlap between the results obtained in different airway diseases. At first glance, this suggests that the $\mathrm{pH}$ of $\mathrm{EBC}$ is a general marker of airway inflammation rather than a disease-specific marker. However, closer inspection suggests that the $\mathrm{pH}$ of EBC in COPD patients exhibits certain unique characteristics. First, there is a clear differentiation between the $\mathrm{pH}$ "normal range" and the $\mathrm{pH}$ observed in COPD patients, which is not observed in other airway diseases. Secondly, a subgroup of patients with stable COPD exhibited very acidic $\mathrm{pH}$, which is not observed in stable asthma. This subgroup of COPD patients may represent a specific disease phenotype and warrants further study.

\section{Phenotyping}

The mechanisms that contribute to airway acidity and its variability in COPD are unclear. KOSTIKAS et al. [37] observed that EBC pH correlated with sputum neutrophilia and FEV1, although this FEV1 relationship was not confirmed in the present authors' COPD population [20]. Further investigation of the mechanisms involved in the generation and variation of acidic EBC pH, as well as the relationship between EBC $\mathrm{pH}$ and different COPD phenotypic characteristics, is required.

\section{Clinical trials}

An observational study in acute asthma, showing that EBC acidity improves with steroid treatment, was the first to suggest that this biomarker might be sensitive to treatment effects [36]. A significant increase in the $\mathrm{pH}$ of EBC was also observed after 6 months' steroid treatment in stable asthma [55]. In a study of serial $\mathrm{pH}$ of EBC measurements in chronic cough, EBC acidification was significantly more common in those patients who subsequently responded symptomatically to proton pump inhibition, supporting the role of airway acidification in refluxassociated cough [76]. However, another study showed no change in the $\mathrm{pH}$ of EBC after treatment with omeprazole, despite clinical improvement of reflux-associated cough [77]. Studies examining the sensitivity of EBC $\mathrm{pH}$ to detect treatment effects in COPD are lacking.

\section{$\mathrm{LTB}_{4}$}

$\mathrm{LTB}_{4}$ is produced from arachidonic acid by 5-lipoxygenase. It is a potent neutrophil chemoattractant and therefore may have a role in the pathogenesis of COPD.

\section{Diagnosis}

Increased levels of EBC $\mathrm{LTB}_{4}$ have been demonstrated in stable COPD patients compared with healthy smokers [43, 54], as well as in healthy smokers compared with nonsmokers [66]. These studies suggest that EBC $\mathrm{LTB}_{4}$ measurements may be used to aid the diagnosis of COPD. However, a different picture emerges when the results of all studies investigating levels of $\mathrm{EBC} \mathrm{LTB}_{4}$ in adults are viewed at the same time (fig. 2). There is a wide variation in absolute levels of EBC LTB between studies, despite the use of the same breath condenser and ELISA kit; values in COPD patients range from 10 [13] to $100 \mathrm{pg} \cdot \mathrm{mL}^{-1}$ [43]. Furthermore, there is an overlap of EBC LTB levels between patients and controls, which argues against the ability of this biomarker to be used in COPD diagnosis. The potential methodological pitfalls associated with $\mathrm{LTB}_{4}$ collection and measurement, including oral contamination and lack 


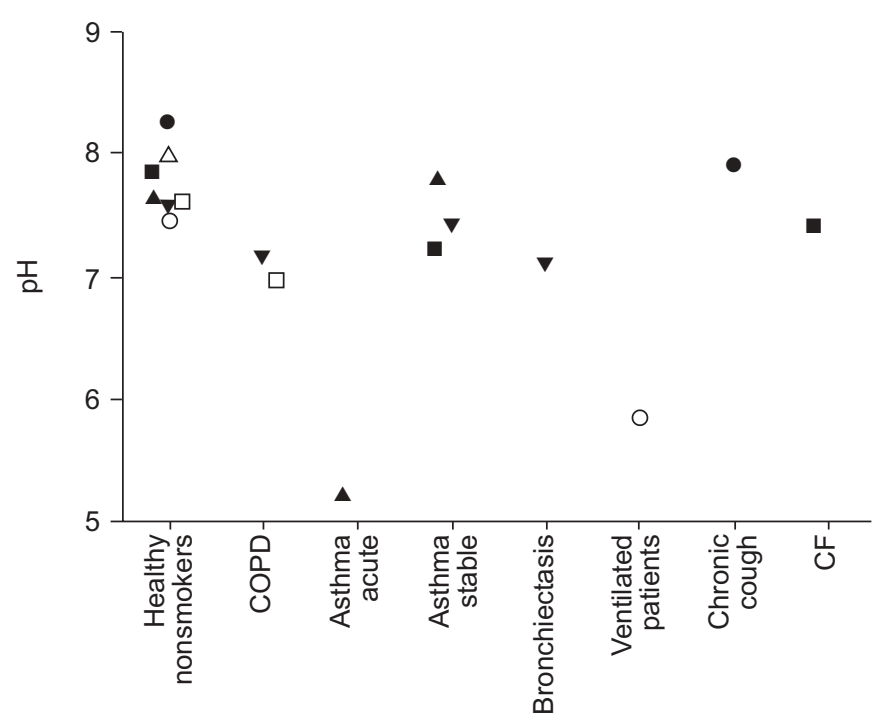

FIGURE 1. Exhaled breath condensate pH, post gas standardisation, in healthy subjects and patients with disease. COPD: chronic obstructive pulmonary disease; CF: cystic fibrosis. $\mathbf{\Lambda}$ : data from [36]; $\mathbf{\nabla}:$ [37]; O: [42]; $\bullet:$ [41]; $\mathbf{\square}:$ [66]; $\square$ : [20]; $\triangle$ : [62]. Data are presented as mean for $\boldsymbol{\Lambda}, \boldsymbol{\nabla}, \bigcirc, \boldsymbol{\square}$ and $\bullet$, and median for $\square$ and $\triangle$

of ELISA sensitivity, have already been reviewed. These methodological issues lead to considerable variability of $\mathrm{LTB}_{4}$ measurements in COPD patients [51] and probably contribute to the lack of reproducibility of data between laboratories.

\section{Phenotyping}

Despite the methodological issues, there are data to support the use of EBC $\mathrm{LTB}_{4}$ measurements in COPD patients, as it is correlated with sputum neutrophilia and may, therefore, be a useful biomarker of the degree of neutrophilic inflammation [54].

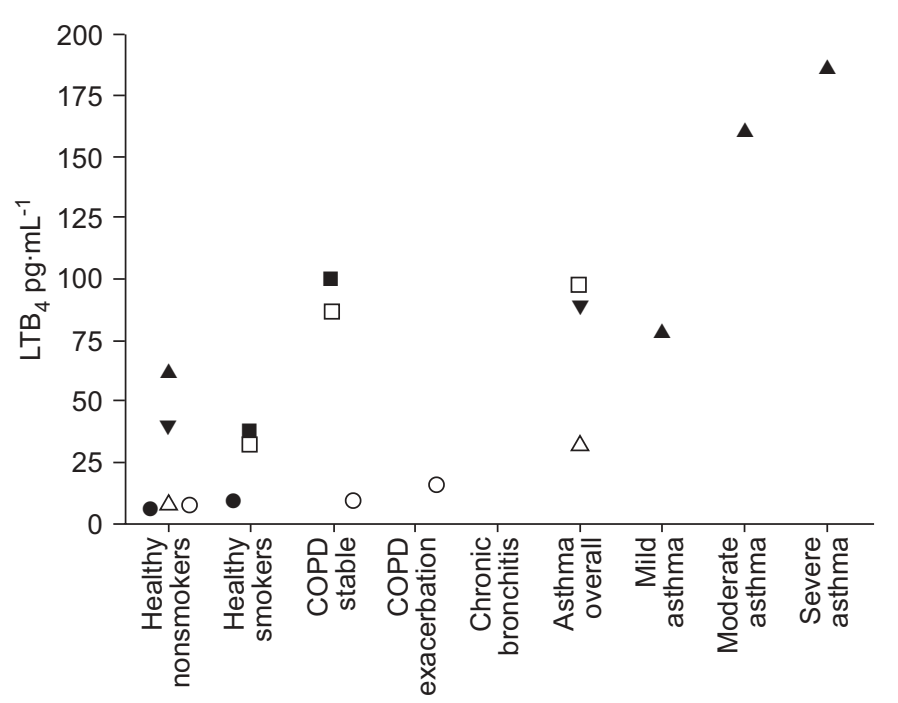

FIGURE 2. Exhaled breath condensate leukotriene $(L T) B_{4}$ in healthy subjects and patients with disease. COPD: chronic obstructive pulmonary disease. $\mathbf{\Lambda}$ : data from [78]; $\mathbf{\nabla}:$ [16]; O: [13]; •: [53]; $\mathbf{\square}:$ [43]; $\square:$ [54]; $\triangle$ : [79]. Data are presented as mean for $\boldsymbol{\Delta}, \boldsymbol{\nabla}, \bigcirc, \bullet, \square$ and $\triangle$, and median for

\section{Exacerbations}

EBC $\mathrm{LTB}_{4}$ has also been observed to increase during COPD exacerbations and fall during recovery, suggesting that this biomarker is an indicator of the inflammatory burden in the airways [13]. Airway neutrophilia is known to increase during COPD exacerbations [80] and further studies are needed to confirm that $\mathrm{LTB}_{4}$ is a biomarker of neutrophilic inflammation during exacerbations.

Cinical trials

The potential of $\mathrm{LTB}_{4}$ as a biomarker in clinical trials has been explored; MONTUSCHI et al. [65] performed a randomised placebo-controlled trial with ibuprofen in 14 patients with COPD, and a follow up open-label uncontrolled study using the COX-2 inhibitor rofecoxib in a separate group of 16 COPD patients. Whereas ibuprofen caused a significant increase in EBC $\mathrm{LTB}_{4}$ compared to placebo, rofecoxib did not, suggesting that this biomarker may sensitively differentiate between selective and nonselective COX inhibition in COPD patients. The mechanism behind this effect is not clear but may indicate that in COPD, COX-1 inhibition can divert arachidonic acid metabolism to produce LTs whereas COX-2 inhibition does not. However, placebo-controlled studies are needed in order to confirm these observations. There is also evidence from asthma trials that $\mathrm{LTB}_{4}$ can be used as a biomarker to detect drug effects, as $\mathrm{LTB}_{4}$ and cysteinyl-LTs were reduced by montelukast, which was associated with improvement in quality-of-life scores [79]. These results require validation in a randomised placebo-controlled trial setting. Reduction in EBC cysteinyl-LTs has also been demonstrated following the treatment of allergic rhinitis with inhaled corticosteroids [81]. No difference in EBC $\mathrm{LTB}_{4}$ levels was observed between steroid-treated and steroid-naïve COPD patients in a study by MONTUSHCI et al. [43], as the cross-sectional design of the study could not definitively exclude an effect of steroids on $\mathrm{LTB}_{4}$.

\section{Prostaglandins}

\section{Diagnosis}

EBC $\mathrm{PGE}_{2}$ is increased in stable COPD patients [43] and in smokers with asthma [56] but not in nonsmokers with asthma $[16,56]$. Conversely, $\mathrm{TXB}_{2}$ is increased in EBC in asthma but is not detectable in patients with COPD $[16,43]$. These observations suggest that the profile of EBC prostaglandins may differ in asthma and COPD.

\section{Clinical trials}

It has been shown that ibuprofen significantly reduced EBC $\mathrm{PGE}_{2}$ compared with placebo in COPD patients, whereas rofecoxib did not, suggesting that this biomarker can sensitively differentiate between selective and nonselective COX inhibition in COPD patients [65]. More studies are needed in order to properly evaluate the potential of $\mathrm{EBC} \mathrm{PGE}_{2}$ as a biomarker of drug effects. Such data should include the definition of normal range and methodological validation, including reproducibility.

\section{Cytokines}

\section{Diagnosis}

COPD is associated with the upregulation of the activity of a complex network of proinflammatory cytokines in the airways. Increased levels of EBC IL-6 and TNF- $\alpha$ (pro-inflammatory 
cytokines) and IL-10 (a regulatory cytokine), have been reported in COPD and healthy smokers, albeit at very low concentrations near or below the limit of the standard curve of the ELISA methods used [63, 66]. GAREY et al. [35] demonstrated higher levels of protein in EBC from smokers compared with nonsmokers, but no difference in the levels of IL-1 $\beta$ or TNF- $\alpha$ between the groups.

\section{Phenotyping}

IL-6 concentrations were found to correlate with smoking history and FEV1 in healthy smokers [66].

\section{Exacerbations}

More recently, a study using a multiplex array kit observed an increase in EBC cytokines (IL-1 $\beta$, IL-6, IL-8, IL-10, IL-12p70 and TNF- $\alpha$ ) in COPD patients with acute exacerbation compared with stable patients [67]. That study suggests that EBC cytokines may be useful biomarkers of COPD exacerbations. This multiplex array technique shows promise but optimisation of sensitivity and reproducibility is required if this method is to be used with more confidence.

\section{Clinical trials}

There is evidence from asthma studies that EBC cytokine measurements (IL-4, IL-8, IL-17, TNF- $\alpha$, chemokine (C-C motif) ligand 5 and transforming growth factor- $\beta$ ) are elevated in patients compared with controls [82] and that inhaled corticosteroids reduce EBC IL-4, but not IL-6, in asthma patients, although the lack of a placebo control means these results should be interpreted with caution. [55].

\section{$\mathrm{H}_{2} \mathrm{O}_{2}$}

Airway $\mathrm{H}_{2} \mathrm{O}_{2}$ is produced by superoxide dismutase-mediated conversion of superoxide anions. $\mathrm{EBC} \mathrm{H}_{2} \mathrm{O}_{2}$ is measured by a spectrophotometric method using horseradish peroxidase.

\section{Diagnosis}

Figure 3 shows that there is some differentiation between EBC $\mathrm{H}_{2} \mathrm{O}_{2}$ levels observed in disease and those observed in healthy subjects, as well as between healthy smokers and COPD patients [68, 69]. However, overlap exists between observed levels in COPD and asthma patients, indicating that this biomarker is not disease specific.

\section{Phenotyping}

In COPD patients, correlations were observed between EBC $\mathrm{H}_{2} \mathrm{O}_{2}$ and FEV1, sputum neutrophils and dyspnoea score, indicating that this mediator reflects disease activity [27].

\section{Exacerbations}

In cross-sectional and longitudinal studies, increased $\mathrm{H}_{2} \mathrm{O}_{2}$ levels have been observed during COPD exacerbations [14, 68]. There is promise for this biomarker for monitoring the burden of oxidative stress associated with exacerbations.

\section{Clinical trials}

There is evidence that EBC $\mathrm{H}_{2} \mathrm{O}_{2}$ can be used as a biomarker in clinical trials. In a double-blind, randomised, placebo-controlled parallel group study, the effect of $N$-acetylcysteine, an antioxidant mucolytic, was studied in 44 COPD patients [70]. There was no change between placebo and treatment groups after

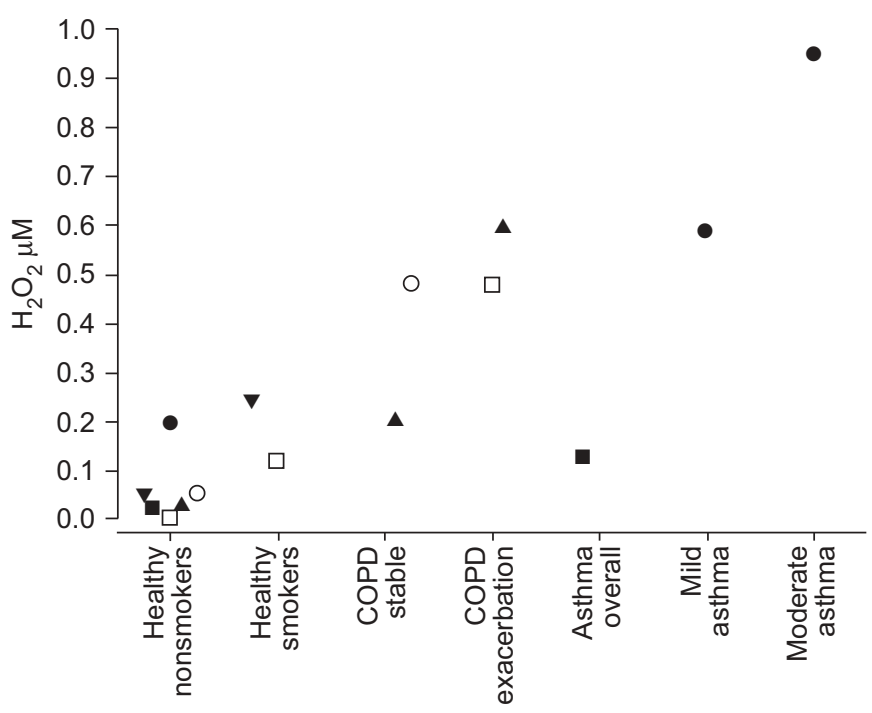

FIGURE 3. Exhaled breath condensate hydrogen peroxide $\left(\mathrm{H}_{2} \mathrm{O}_{2}\right)$ in healthy subjects and patients with disease. COPD: chronic obstructive pulmonary disease. $\boldsymbol{\Delta}$ : data from [68]; $\mathbf{\nabla : ~ [ 8 3 ] ; ~} \bigcirc:$ [69]; $\bullet:$ [28]; $\mathbf{\square}:$ [84]; $\square:$ [14]. Data are presented as mean.

6 months, but after 9 and 12 months, the treatment group exhaled significantly less $\mathrm{H}_{2} \mathrm{O}_{2}$ than the placebo group. The effects of inhaled corticosteroids on $\mathrm{EBC} \mathrm{H}_{2} \mathrm{O}_{2}$ is unclear, as both inhaled beclomethasone and fluticasone propionate reduced $\mathrm{H}_{2} \mathrm{O}_{2}$ after 4 weeks' treatment, but there was no placebo control to compare [71], while EBC $\mathrm{H}_{2} \mathrm{O}_{2}$ did not change after 2 weeks' treatment with inhaled beclomethasone compared with placebo in a cross-over study in COPD patients [72]. Overall, these intervention studies suggest promise for EBC $\mathrm{H}_{2} \mathrm{O}_{2}$ measurements to be used to sensitively detect treatment effects in COPD, although further well-designed studies are needed to prove this.

\section{8-Isoprostane}

8-Isoprostane is formed by the free radical peroxidation of arachidonic acid and is a putatative marker of oxidative stress levels in the lungs.

\section{Diagnosis}

Individual studies have shown higher levels of EBC 8isoprostane in stable COPD patients compared with healthy controls $[27,58,84]$ and in healthy smokers compared with nonsmokers [58]. However, mean values of 8 -isoprostane in COPD patients have varied across studies ranging from 9 [13] to $47 \mathrm{pg} \cdot \mathrm{mL}^{-1}$ [27], despite the use of identical methods (fig. 4). This may be attributable to differences in condenser coatings or ELISA-sensitivity issues already discussed. Patients with asthma also have elevated EBC 8-isoprostane, indicating that it is not a disease-specific biomarker of oxidative stress [86].

\section{Phenotyping}

No correlations have been observed between 8-isoprostane and FEV1, smoking history, sputum cells or dyspnoea score in COPD studies [27, 58]. However, Ko et al. [85] observed significantly higher concentrations of EBC 8-isoprostane in those with severe compared with mild-to-moderate COPD. 


\section{Exacerbations}

There is evidence that EBC 8-isoprostane levels are raised during exacerbations [13].

\section{Clinical trials}

There are no published clinical trials in COPD to evaluate EBC 8-isoprostane measurements in this setting, although no reduction in this biomarker was observed when patients with asthma were treated with inhaled corticosteroids [87].

\section{Other markers of oxidative stress}

\section{Diagnosis}

Lipid peroxidation results in the production of aldehydes that can be measured in EBC by LC-tandem MS. Levels of hexanal and heptanal were increased in stable COPD compared with nonsmoking controls, and malondialdehyde was increased compared with smoking controls [9]. Further studies of these EBC biomarkers are needed to address the issues of reproducibility and changes caused by exacerbations or therapeutic interventions.

\section{Nitrogen oxides}

$\mathrm{NO}$ is a highly reactive free radical that is stabilised ultimately as $\mathrm{NO}_{2}^{-}$and $\mathrm{NO}_{3}^{-}$(nitrogen oxides $\left(\mathrm{NO}_{\mathrm{x}}\right)$ ) or in biological complexes with thiols to form nitrosothiols (RS-NO). In the presence of oxidative stress, the reaction between $\mathrm{NO}$ and superoxide anions yields peroxynitrite, which in turn leads to the formation of harmful nitrotyrosine (NT) [88]. $\mathrm{NO}_{\mathrm{x}}$ are commonly measured by the Greiss reaction [89], which is a diazotisation reaction using the reagents sulphanilamide and naphthylethyllene dihydrochloride under acidic conditions (usually phosphoric acid) to detect $\mathrm{NO}_{2}{ }^{-}$spectophotometrically. $\mathrm{NO}_{3}{ }^{-}$is quantitated after enzymatic reduction to $\mathrm{NO}_{2}{ }^{-}$and then measured as described. Other less-commonly used assays include the fluorimetric 2,3-diaminonapthalene method [60, 90], chemiluminescence and ion chromatography [89, 91, 92].

\section{Diagnosis}

Table 4 summarises the studies that have examined levels of $\mathrm{NO}_{2}^{-}$and/or $\mathrm{NO}_{3}^{-}$in EBC. There is inconsistency between study results in smokers with normal lung function, as both increased $[35,93]$ and normal $[60,73] \mathrm{NO}_{\mathrm{x}}$ levels have been observed in smokers compared with nonsmoking controls. Higher levels of $\mathrm{NO}_{2}^{-}$were observed in COPD patients

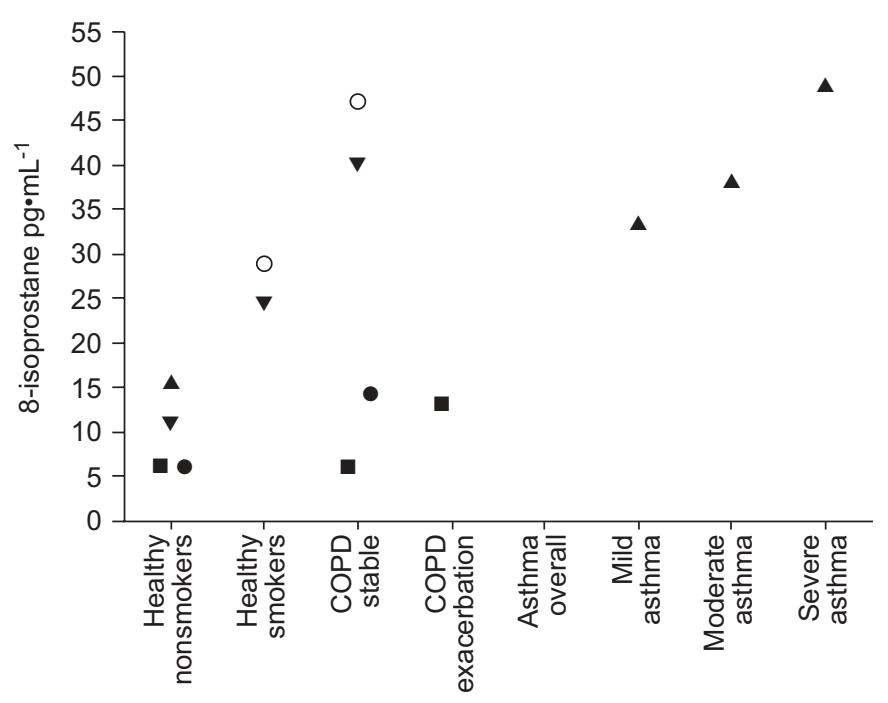

FIGURE 4. Exhaled breath condensate 8-isoprostane in healthy subjects and patients with disease. $\mathbf{\Delta}$ : data from [86]; $\mathbf{\nabla}:$ [58]; ○: [27]; - : [85]; $\mathbf{\square}:$ [13]. Data are presented as mean.

compared with smoking and nonsmoking controls [73], whereas $\mathrm{NO}_{3}{ }^{-}$levels in COPD have been found to be similar [93]. In asthma, higher $\mathrm{NO}_{2}^{-}[33,93]$, total $\mathrm{NO}_{2}^{-} / \mathrm{NO}_{3}^{-}$and $\mathrm{NO}_{3}^{-}$[93] levels have been observed.

In suppurative conditions such as CF [39] and COPD [94] where mucus production can cause reduced exhaled $\mathrm{NO}$ levels, measuring EBC NOx may have advantages [19, 33, 39, 73] as gaseous $\mathrm{NO}$ is encouraged to interact with aqueous ALF giving rise to $\mathrm{NO}_{x}[95]$.

\section{Clinical trials}

Exhaled NO levels have been widely used to measure inhaled corticosteroid effects in patients with asthma, and also in exsmokers with COPD [72]. Similarly, in patients with asthma, budesonide caused a significant reduction in $\mathrm{EBC} \mathrm{NO}_{\mathrm{x}}$ levels compared with placebo [87]. The potential use of EBC $\mathrm{NO}_{x}$ measurements as biomarkers of drug effects needs to be further studied in COPD, perhaps in specific subgroups, such as ex-smokers.

TABLE 4 Nitrate $\left(\mathrm{NO}_{3}{ }^{-}\right)$and nitrite $\left(\mathrm{NO}_{2}{ }^{-}\right)$levels in exhaled breath condensate

\begin{tabular}{|c|c|c|c|c|c|c|c|}
\hline Mediator $\mu \mathrm{M}$ & First author [ref.] & Method & Nonsmokers & Healthy smokers & Mild asthma & Severe asthma & COPD \\
\hline $\mathrm{NO}_{2}^{-}$ & CORRADI [73] & Greiss & 0.45 & 0.44 & 0.63 & $1.04^{\star \star}$ & 2.62 ** \\
\hline $\mathrm{NO}_{2}{ }^{-} / \mathrm{NO}_{3}{ }^{-}$ & GANAS [33] & Greiss & 0.63 & \multicolumn{4}{|c|}{$1.08^{\star *}$} \\
\hline $\mathrm{NO}_{3}^{-}$median & CoRRADI [93] & Chromato-graphic & 9.6 & $62.5^{\star \star}$ & \multicolumn{2}{|c|}{$68.0 * \star$} & 24.1 \\
\hline $\mathrm{NO}_{2}^{-}$ & BALINT [60] & DAN & 3.2 & 2.4 & & & \\
\hline $\mathrm{NO}_{2}^{-} / \mathrm{NO}_{3}^{-}$ & & & 16.0 & 20.2 & & & \\
\hline $\mathrm{NO}_{2}^{-}$ & GaREY [35] & Greiss & 16.2 & $24.7^{\star \star}$ & & & \\
\hline
\end{tabular}

Data are presented as mean, unless otherwise stated. COPD: chronic obstructive pulmonary disease; DAN: 2,3-diaminonaphthalene. **: p<0.01 compared with nonsmokers. 


\begin{tabular}{|c|c|c|c|c|}
\hline Biomarker & Between-subject SD & Effect size & $80 \%$ power & $90 \%$ power \\
\hline EBC $\mathrm{pH}$ & & 0.30 & 175 & 225 \\
\hline \multirow[t]{3}{*}{ EBC 8-isoprostane $\mathrm{pg} \cdot \mathrm{mL}^{-1}$} & 37.6 & 25 & 50 & 35 \\
\hline & & 10 & 200 & 250 \\
\hline & & 4 & $>300$ & $>300$ \\
\hline $\mathrm{EBC} \mathrm{LTB}_{4} \mathrm{pg} \cdot \mathrm{mL}^{-1}$ & 11.6 & 16 & 10 & 12 \\
\hline
\end{tabular}

EBC: exhaled breath condensate; LT: leukotriene.

\section{Nitrotyrosine}

\section{Diagnosis}

EBC studies have measured NT using a specific enzyme immunoassay kit with a detection limit of $3.9 \mathrm{ng} \cdot \mathrm{mL}^{-1}$. Mild steroid-naïve asthmatics had significantly higher levels of NT than healthy controls but levels were reduced in those treated with ICS with moderate and severe disease [78]. Although NT measurements have been performed in induced sputum of COPD patients, with increased levels compared with controls and inhibition by the xanthine oxidase inhibitor allopurinol, there have been no studies using this method in EBC from COPD patients [96].

\section{Nitrosothiols}

Diagnosis

Nitrosothiols (RS-NO) are measured using a commercially available assay (Oxonon; detection limit $0.025 \mu \mathrm{M}$ ) based on the cleavage of RS-NO to release NO, which upon rapid oxidation forms $\mathrm{NO}_{2}{ }^{-}$and is detected colourimetrically. Higher RS-NO levels were observed in smokers compared with nonsmokers in one study [73] but this was not confirmed in another study [60]. CORRADI et al. [73] also observed significantly higher levels of RS-NO in COPD ex-smokers, CF and severe asthma patients, compared with healthy nonsmokers.
More studies using this measurement in COPD patients are needed in order to properly define reproducibility and the potential of this biomarker as a clinical tool, for example, in monitoring exacerbations or in clinical trials.

\section{Power calculations}

The between-subject variability can be used for power calculations to estimate the number of subjects required in clinical trials of therapeutic interventions. EBC $\mathrm{pH}, \mathrm{LTB}_{4}$ and 8isoprostane variability data $[20,51]$ were used, to estimate the number of subjects that would be required to obtain an estimated 80 or $90 \%$ power in order to detect certain effect sizes (table 5). The clinically important effect size for EBC biomarkers is not known. Therefore, effect sizes were determined from the literature as described in table 6 .

\section{DISCUSSION}

In the present review the potential of EBC mediators to be used as biomarkers in COPD has been explored. Initially, methodological issues were considered. The present authors conclude that each potential EBC mediator must be subject to separate and meticulous method validation. Many issues regarding the collection of $\mathrm{EBC}$, including pattern of breathing $[9,12,16-18]$, collection device used [6-10], and the effect of oral contamination $[12,25,26]$ are mediator specific. For certain

\section{TABLE 6 Clinically important effect sizes for exhaled breath condensate biomarkers}

\begin{tabular}{lcc} 
First author [ref.] & Biomarker & Rationale \\
\hline HUNT [36] & $\mathrm{pH}$ & Acute asthma: $\mathrm{pH}$ increased by 2.0 \\
CARPAGNANO [55] & & Stable asthma: $6 / 12$ steroid treatment, $\mathrm{pH}$ increased by 0.3 \\
BIERNACKI [13] & 8-isoprostane & $\mathrm{COPD}$ exacerbations: 8 -isoprostane decreased by $4 \mathrm{pg} \cdot \mathrm{mL}^{-1}$ \\
BIERNACKI [13] & $\mathrm{LTB}_{4}$ & $\mathrm{COPD}$ exacerbations: $\mathrm{LTB}_{4}$ decreased by $6 \mathrm{pg} \cdot \mathrm{mL}^{-1}$ \\
BIERNACKI [79] & & Asthma montelukast: $\mathrm{LTB}_{4}$ decreased by $16 \mathrm{pg} \cdot \mathrm{mL}^{-1}$ in 4 weeks \\
\hline
\end{tabular}


EBC mediators, particularly cytokines, the ELISA method has been associated with inadequate assay sensitivity and specificity. Methods such as GC/MS may prove more successful but require further validation [44-49].

A high degree of within-subject variability has been demonstrated for many EBC mediators, which can be more pronounced in COPD patients compared with healthy subjects $[20,51,53,54]$. This is an important observation as it indicates an increased tendency for EBC composition to vary over time in COPD patients.

In terms of method validation, $\mathrm{pH}$ has been the most extensively studied EBC mediator. Mean $\mathrm{pH}$ levels are consistent in healthy subjects [64] and there is good differentiation between health and disease [20,37]. Furthermore, a subset of COPD patients exhibit a very low $\mathrm{pH}$, of EBC which may be indicative of a specific COPD phenotype [20, 37]. However, the $\mathrm{pH}$ of $\mathrm{EBC}$ is significantly more variable in COPD patients than in healthy subjects and the reasons for this are unknown [20]. There is currently little published information regarding the identity of the acids that cause low $\mathrm{pH}$ values in EBC samples. Further research is warranted to explore the mechanisms generating acidic $\mathrm{pH}$ in the airways and to examine the sensitivity of the $\mathrm{pH}$ of $\mathrm{EBC}$ to detect exacerbation and treatment effects in COPD.

The mediators 8-isoprostane and $\mathrm{LTB}_{4}$ have been extensively reported in EBC but levels have varied considerably within the same subject groups, despite the use of identical analytical methods [13, 27, 43]. This is likely to be due to methodological issues, such as condenser coatings, mouth contamination and assay sensitivity. The lack of differentiation of levels of these mediators between disease groups and healthy subjects clearly limits their use in COPD diagnosis. However, despite the methodological issues, there is some evidence supporting the role of EBC 8-isoprostane and $\mathrm{LTB}_{4}$ as markers of exacerbations in COPD patients [13] and some promising preliminary data showing the utility of $\mathrm{EBC}^{\mathrm{LTB}} \mathrm{TB}_{4}$ as a biomarker in clinical trials [65]. Improvements to the collection and analysis methods for 8-isoprostane and $\mathrm{LTB}_{4}$ may improve their potential as biomarkers in COPD.

With regard to $\mathrm{COPD}, \mathrm{EBC} \mathrm{H}_{2} \mathrm{O}_{2}$ perhaps shows the most evidence for use as a biomarker for monitoring exacerbations, as well as in clinical trials [14, 68, 70]. Studies have shown relatively good reproducibility in both healthy subjects and COPD patients, if constant minute ventilation is maintained [27, 34]. EBC $\mathrm{H}_{2} \mathrm{O}_{2}$ levels exhibit marked overlap between diseases, indicating a lack of disease specificity, again precluding its use as a diagnostic biomarker in COPD [28, 68, 69, 84]. However, this lack of disease specificity may not adversely affect its potential as a biomarker of treatment response in COPD.

The use of ELISA for measuring cytokines in EBC has been hampered by assay sensitivity. The use of cytokine arrays has proved more promising, as biomarkers of COPD exacerbations can be detected [67]. Further methodological optimisation of this technique is warranted.

The study of EBC biomarkers is a rapidly evolving field and the present evaluation at this point in time could easily change with new findings. It can be seen in table 3 that there is much information still needed to complete the evaluation of the potential of EBC biomarkers in COPD. It should also be stressed that biomarkers showing potential for exacerbation monitoring or response to treatment intervention may be different to those useful in diagnosis or disease phenotyping.

The use of mass spectrometry or nuclear magnetic resonance profiling of exhaled breath condensate may allow hypothesisfree profiling of biomarkers, rather than a traditional hypothesis-driven approach [49]. These techniques have the advantage of increased sensitivity but require complex data analysis in order to identify single mediators or patterns of mediators linked to clinical status. Hypothesis generation from such profiling may lead to more rational selection of biomarkers for specific analysis.

\section{REFERENCES}

1 Donaldson GC, Seemungal TA, Patel IS, et al. Airway and systemic inflammation and decline in lung function in patients with COPD. Chest 2005; 128: 1995-2004.

2 Leigh R, Pizzichini MM, Morris MM, Maltais F, Hargreave FE, Pizzichini E. Stable COPD: predicting benefit from high-dose inhaled corticosteroid treatment. Eur Respir J 2006; 27: 964-971.

3 Brightling CE, McKenna S, Hargadon B, et al. Sputum eosinophilia and the short term response to inhaled mometasone in chronic obstructive pulmonary disease. Thorax 2005; 60: 193-198.

4 Hurst JR, Donaldson GC, Perera WR, et al. Use of plasma biomarkers at exacerbation of chronic obstructive pulmonary disease. Am J Respir Crit Care Med 2006; 174: 867-874.

5 Horvath I, Hunt J, Barnes PJ, et al. Exhaled breath condensate: methodological recommendations and unresolved questions. Eur Respir J 2005; 26: 523-548.

6 Prieto L, Ferrer A, Palop J, Domenech J, Llusar R, Rojas R. Differences in exhaled breath condensate $\mathrm{pH}$ measurements between samples obtained with two commercial devices. Respir Med 2007; 101: 1715-1720.

7 Soyer OU, Dizdar EA, Keskin O, Lilly C, Kalayci O. Comparison of two methods for exhaled breath condensate collection. Allergy 2006; 61: 1016-1018.

8 Leung TF, Li CY, Yung E, Liu EK, Lam CW, Wong GW. Clinical and technical factors affecting $\mathrm{pH}$ and other biomarkers in exhaled breath condensate. Pediatr Pulmonol 2006; 41: 87-94.

9 Corradi M, Rubinstein I, Andreoli R, et al. Aldehydes in exhaled breath condensate of patients with chronic obstructive pulmonary disease. Am J Respir Crit Care Med 2003; 167: 1380-1386.

10 Rosias PP, Robroeks CM, Niemarkt HJ, et al. Breath condenser coatings affect measurement of biomarkers in exhaled breath condensate. Eur Respir J 2006; 28: 1036-1041.

11 Ishibashi $\mathrm{T}$, Himeno $\mathrm{M}$, Imaizumi $\mathrm{N}$, et al. $\mathrm{NO}(\mathrm{x})$ contamination in laboratory ware and effect of countermeasures. Nitric Oxide 2000; 4: 516-525.

12 Vaughan J, Ngamtrakulpanit L, Pajewski TN, et al. Exhaled breath condensate $\mathrm{pH}$ is a robust and reproducible assay of airway acidity. Eur Respir J 2003; 22: 889-894. 
13 Biernacki WA, Kharitonov SA, Barnes PJ. Increased leukotriene B4 and 8-isoprostane in exhaled breath condensate of patients with exacerbations of COPD. Thorax 2003; 58: 294-298.

14 Gerritsen WB, Asin J, Zanen P, van den Bosch JM, Haas FJ. Markers of inflammation and oxidative stress in exacerbated chronic obstructive pulmonary disease patients. Respir Med 2005; 99: 84-90.

15 Vogelberg C, Hirsch T, Rösen-Wolff A, Kerkmann ML, Leupold W. Pseudomonas aeruginosa and Burkholderia cepacia cannot be detected by PCR in the breath condensate of patients with cystic fibrosis. Pediatr Pulmonol 2003; 36: 348-352.

16 Montuschi P, Barnes PJ. Exhaled leukotrienes and prostaglandins in asthma. J Allergy Clin Immunol 2002; 109: 615-620.

17 Schleiss MB, Holz O, Behnke M, Richter K, Magnussen H, Jörres RA. The concentration of hydrogen peroxide in exhaled air depends on expiratory flow rate. Eur Respir J 2000; 16: 1115-1118.

18 McCafferty JB, Bradshaw TA, Tate S, Greening AP, Innes JA. Effects of breathing pattern and inspired air conditions on breath condensate volume, $\mathrm{pH}$, nitrite, and protein concentrations. Thorax 2004; 59: 694-698.

19 Ho LP, Innes JA, Greening AP. Nitrite levels in breath condensate of patients with cystic fibrosis is elevated in contrast to exhaled nitric oxide. Thorax 1998; 53: 680-684.

20 Borrill Z, Starkey C, Vestbo J, Singh D. Reproducibility of exhaled breath condensate $\mathrm{pH}$ in chronic obstructive pulmonary disease. Eur Respir J 2005; 25: 269-274.

21 Vass G, Huszár E, Barát E, et al. Comparison of nasal and oral inhalation during exhaled breath condensate collection. Am J Respir Crit Care Med 2003; 167: 850-855.

22 Effros RM, Casaburi R, Su J, et al. The effects of volatile salivary acids and bases on exhaled breath condensate $\mathrm{pH}$. Am J Respir Crit Care Med 2006; 173: 386-392.

23 Effros RM. Exhaled breath condensate pH. Eur Respir J 2004; 23: 961-962.

24 Wells K, Vaughan J, Pajewski TN, et al. Exhaled breath condensate $\mathrm{pH}$ assays are not influenced by oral ammonia. Thorax 2005; 60: 27-31.

25 Marteus H, Törnberg DC, Weitzberg E, Schedin U, Alving K. Origin of nitrite and nitrate in nasal and exhaled breath condensate and relation to nitric oxide formation. Thorax 2005; 60: 219-225.

26 Gaber F, Acevedo F, Delin I, et al. Saliva is one likely source of leukotriene B4 in exhaled breath condensate. Eur Respir J 2006; 28: 1229-1235.

27 Kostikas K, Papatheodorou G, Psathakis K, Panagou P, Loukides S. Oxidative stress in expired breath condensate of patients with COPD. Chest 2003; 124: 1373-1380.

28 Loukides S, Bouros D, Papatheodorou G, Panagou P, Siafakas NM. The relationships among hydrogen peroxide in expired breath condensate, airway inflammation, and asthma severity. Chest 2002; 121: 338-346.

29 Effros RM, Hoagland KW, Bosbous M, et al. Dilution of respiratory solutes in exhaled condensates. Am J Respir Crit Care Med 2002; 165: 663-669.

30 Gessner C, Kuhn H, Seyfarth HJ, et al. Factors influencing breath condensate volume. Pneumologie 2001; 55: 414-419.
31 Effros RM, Biller J, Foss B, et al. A simple method for estimating respiratory solute dilution in exhaled breath condensates. Am J Respir Crit Care Med 2003; 168: 1500-1505.

32 Mercer PF, Shute JK, Bhowmik A, Donaldson GC, Wedzicha JA, Warner JA. MMP-9, TIMP-1 and inflammatory cells in sputum from COPD patients during exacerbation. Respir Res 2005; 6: 151.

33 Ganas K, Loukides S, Papatheodorou G, Panagou P, Kalogeropoulos N. Total nitrite/nitrate in expired breath condensate of patients with asthma. Respir Med 2001; 95: 649-654.

34 van Beurden WJ, Harff GA, Dekhuijzen PNR, van den Bosch MJ, Creemers JP, Smeenk FW. An efficient and reproducible method for measuring hydrogen peroxide in exhaled breath condensate. Respir Med 2002; 96: 197-203.

35 Garey KW, Neuhauser MM, Robbins RA, Danziger LH, Rubinstein I. Markers of inflammation in exhaled breath condensate of young healthy smokers. Chest 2004; 125: 22-26.

36 Hunt JF, Fang K, Malik R, et al. Endogenous airway acidification. Implications for asthma pathophysiology. Am J Respir Crit Care Med 2000; 161: 694-699.

37 Kostikas K, Papatheodorou G, Ganas K, Psathakis K, Panagou P, Loukides S. pH in expired breath condensate of patients with inflammatory airway diseases. Am J Respir Crit Care Med 2002; 165: 1364-1370.

38 Kullmann T, Barta I, Lazar Z, et al. Exhaled breath condensate $\mathrm{pH}$ standardised for $\mathrm{CO}_{2}$ partial pressure. Eur Respir J 2007; 29: 496-501.

39 Ojoo JC, Mulrennan SA, Kastelik JA, Morice AH, Redington AE. Exhaled breath condensate $\mathrm{pH}$ and exhaled nitric oxide in allergic asthma and in cystic fibrosis. Thorax 2005; 60: 22-26.

40 Borrill ZL, Smith JA, Naylor J, Woodcock AA, Singh D. The effect of gas standardisation on exhaled breath condensate pH. Eur Respir J 2006; 28: 251-252.

41 Niimi A, Nguyen LT, Usmani O, Mann B, Chung KF. Reduced $\mathrm{pH}$ and chloride levels in exhaled breath condensate of patients with chronic cough. Thorax 2004; 59: 608-612.

42 Gessner C, Hammerschmidt S, Kuhn H, et al. Exhaled breath condensate acidification in acute lung injury. Respir Med 2003; 97: 1188-1194.

43 Montuschi P, Kharitonov SA, Ciabattoni G, Barnes PJ. Exhaled leukotrienes and prostaglandins in COPD. Thorax 2003; 58: 585-588.

44 Montuschi P, Ragazzoni E, Valente S, et al. Validation of 8isoprostane and prostaglandin $\mathrm{E}(2)$ measurements in exhaled breath condensate. Inflamm Res 2003; 52: 502-507.

45 Montuschi P, Ragazzoni E, Valente S, et al. Validation of leukotriene B4 measurements in exhaled breath condensate. Inflamm Res 2003; 52: 69-73.

46 Cáp P, Chládek, J Pehal F, et al. Gas chromatography/mass spectrometry analysis of exhaled leukotrienes in asthmatic patients. Thorax 2004; 59: 465-470.

47 Montuschi P, Martello S, Felli M, Mondino C, Chiarotti M. Ion trap liquid chromatography/tandem mass spectrometry analysis of leukotriene B4 in exhaled breath condensate. Rapid Commun Mass Spectrom 2004; 18: 2723-2729.

48 Huszár E, Vass G, Vizi E, et al. Adenosine in exhaled breath condensate in healthy volunteers and in patients with asthma. Eur Respir J 2002; 20: 1393-1398. 
49 Carraro S, Rezzi S, Reniero F, et al. Metabolomics applied to exhaled breath condensate in childhood asthma. Am J Respir Crit Care Med 2007; 175: 986-990.

50 van Beurden WJ, Dekhuijzen PN, Harff GA, Smeenk FW. Variability of exhaled hydrogen peroxide in stable COPD patients and matched healthy controls. Respiration 2002; 69: 211-216.

51 Borrill ZL, Starkey RC, Singh SD. Variability of exhaled breath condensate leukotriene B4 and 8-isoprostane in COPD patients. Int J Chron Obstruct Pulmon Dis 2007; 2: 71-76.

52 Balint B, Kharitonov SA, Hanazawa $\mathrm{T}$, et al. Increased nitrotyrosine in exhaled breath condensate in cystic fibrosis. Eur Respir J 2001; 17: 1201-1207.

53 Carpagnano GE, Barnes PJ, Geddes DM, Hodson ME, Kharitonov SA. Increased leukotriene B4 and interleukin-6 in exhaled breath condensate in cystic fibrosis. Am J Respir Crit Care Med 2003; 167: 1109-1112.

54 Kostikas K, Gaga M, Papatheodorou G, Karamanis T, Orphanidou D, Loukides S. Leukotriene B4 in exhaled breath condensate and sputum supernatant in patients with COPD and asthma. Chest 2005; 127: 1553-1559.

55 Carpagnano GE, Foschino Barbaro MP, Resta O, et al. Exhaled markers in the monitoring of airways inflammation and its response to steroid's treatment in mild persistent asthma. Eur J Pharmacol 2005; 519: 175-181.

56 Kostikas K, Papatheodorou G, Psathakis K, Panagou P, Loukides S. Prostaglandin E2 in the expired breath condensate of patients with asthma. Eur Respir J 2003; 22: 743-747.

57 Bland JM, Altman DG. Statistical methods for assessing agreement between two methods of clinical measurement. Lancet 1986; 1: 307-310.

58 Montuschi P, Collins JV, Ciabattoni G, et al. Exhaled 8isoprostane as an in vivo biomarker of lung oxidative stress in patients with COPD and healthy smokers. Am J Respir Crit Care Med 2000; 162: 1175-1177.

59 Nowak D, Kalucka S, Białasiewicz P, Król M. Exhalation of $\mathrm{H}_{2} \mathrm{O}_{2}$ and thiobarbituric acid reactive substances (TBARs) by healthy subjects. Free Radic Biol Med 2001; 30: 178-186.

60 Balint B, Donnelly LE, Hanazawa T, Kharitonov SA, Barnes PJ. Increased nitric oxide metabolites in exhaled breath condensate after exposure to tobacco smoke. Thorax 2001; 56: 456-461.

61 Calverley PM, Lee A, Towse L, van Noord J, Witek TJ, Kelsen S. Effect of tiotropium bromide on circadian variation in airflow limitation in chronic obstructive pulmonary disease. Thorax 2003; 58: 855-860.

62 Paget-Brown AO, Ngamtrakulpanit L, Smith A, et al. Normative data for $\mathrm{pH}$ of exhaled breath condensate. Chest 2006; 129: 426-430.

63 Carpagnano GE, Foschino Barbaro MP, Cagnazzo M, et al. Use of exhaled breath condensate in the study of airway inflammation after hypertonic saline solution challenge. Chest 2005; 128: 3159-3166.

64 Antczak A, Kharitonov SA, Montuschi P, Gorski P, Barnes PJ. Inflammatory response to sputum induction measured by exhaled markers. Respiration 2005; 72: 594599.

65 Montuschi P, Macagno F, Parente P, et al. Effects of cyclooxygenase inhibition on exhaled eicosanoids in patients with COPD. Thorax 2005; 60: 827-833.
66 Carpagnano GE, Kharitonov SA, Foschino-Barbaro MP, Resta O, Gramiccioni E, Barnes PJ. Increased inflammatory markers in the exhaled breath condensate of cigarette smokers. Eur Respir J 2003; 21: 589-593.

67 Gessner C, Scheibe R, Wötzel M, et al. Exhaled breath condensate cytokine patterns in chronic obstructive pulmonary disease. Respir Med 2005; 99: 1229-1240.

68 Dekhuijzen PN, Aben KK, Dekker I, et al. Increased exhalation of hydrogen peroxide in patients with stable and unstable chronic obstructive pulmonary disease. Am J Respir Crit Care Med 1996; 154: 813-816.

69 Nowak D, Kasielski M, Antczak A, Pietras T, Bialasiewicz P. Increased content of thiobarbituric acidreactive substances and hydrogen peroxide in the expired breath condensate of patients with stable chronic obstructive pulmonary disease: no significant effect of cigarette smoking. Respir Med 1999; 93: 389-396.

70 Kasielski M, Nowak D. Long-term administration of $N$ acetylcysteine decreases hydrogen peroxide exhalation in subjects with chronic obstructive pulmonary disease. Respir Med 2001; 95: 448-456.

71 van Beurden WJ, Harff GA, Dekhuijzen PN, van der PoelSmet SM, Smeenk FW. Effects of inhaled corticosteroids with different lung deposition on exhaled hydrogen peroxide in stable COPD patients. Respiration 2003; 70: 242-248.

72 Ferreira IM, Hazari MS, Gutierrez C, Zamel N, Chapman KR. Exhaled nitric oxide and hydrogen peroxide in patients with chronic obstructive pulmonary disease: effect of inhaled beclomethasone. Am J Respir Crit Care Med 2001; 164: 1012-1015.

73 Corradi M, Montuschi P, Donnelly LE, Pesci A, Kharitonov SA, Barnes PJ. Increased nitrosothiols in exhaled breath condensate in inflammatory airway diseases. Am J Respir Crit Care Med 2001; 163: 854-858.

74 Ricciardolo FL, Gaston B, Hunt J. Acid stress in the pathology of asthma. J Allergy Clin Immunol 2004; 113: 610-619.

75 Carpagnano GE, Barnes PJ, Francis J, Wilson N, Bush A, Kharitonov SA. Breath condensate $\mathrm{pH}$ in children with cystic fibrosis and asthma: a new noninvasive marker of airway inflammation? Chest 2004; 125: 2005-2010.

76 Hunt J, Yu Y, Burns J, et al. Identification of acid reflux cough using serial assays of exhaled breath condensate pH. Cough 2006; 2: 3.

77 Torrego A, Cimbollek S, Hew M, Chung KF. No effect of omeprazole on $\mathrm{pH}$ of exhaled breath condensate in cough associated with gastro-oesophageal reflux. Cough 2005; 1: 10.

78 Hanazawa T, Kharitonov SA, Barnes PJ. Increased nitrotyrosine in exhaled breath condensate of patients with asthma. Am J Respir Crit Care Med 2000; 162: 1273-1276.

79 Biernacki WA, Kharitonov SA, Biernacka HM, Barnes PJ. Effect of montelukast on exhaled leukotrienes and quality of life in asthmatic patients. Chest 2005; 128: 1958-1963.

80 Papi A, Bellettato CM, Braccioni F, et al. Infections and airway inflammation in chronic obstructive pulmonary disease severe exacerbations. Am J Respir Crit Care Med 2006; 173: 1114-1121.

81 Failla M, Biondi G, Provvidenza Pistorio M, et al. Intranasal steroid reduces exhaled bronchial cysteinyl leukotrienes in allergic patients. Clin Exp Allergy 2006; 36: 325-330.

82 Matsunaga K, Yanagisawa S, Ichikawa T, et al. Airway cytokine expression measured by means of protein array in 
exhaled breath condensate: correlation with physiologic properties in asthmatic patients. J Allergy Clin Immunol 2006; 118: 84-90.

83 Nowak D, Antczak A, Krol M, Pietras T, Shariati B, Bialasiewicz P, Jeczkowski K, Kula P. Increased content of hydrogen peroxide in the expired breath of cigarette smokers. Eur Respir J 1996; 9: 652-657.

84 Emelyanov A, Fedoseev G, Abulimity A, et al. Elevated concentrations of exhaled hydrogen peroxide in asthmatic patients. Chest 2001; 120: 1136-1139.

85 Ko FW, Lau CY, Leung TF, Wong GW, Lam CW, Hui DS. Exhaled breath condensate levels of 8-isoprostane, growth related oncogene $\alpha$ and monocyte chemoattractant protein-1 in patients with chronic obstructive pulmonary disease. Respir Med 2006; 100: 630-638.

86 Montuschi P, Corradi M, Ciabattoni G, Nightingale J, Kharitonov SA, Barnes PJ. Increased 8-isoprostane, a marker of oxidative stress, in exhaled condensate of asthma patients. Am J Respir Crit Care Med 1999; 160: 216-220.

87 Kharitonov SA, Donnelly LE, Montuschi P, Corradi M, Collins JV, Barnes PJ. Dose-dependent onset and cessation of action of inhaled budesonide on exhaled nitric oxide and symptoms in mild asthma. Thorax 2002; 57: 889-896.

88 Ricciardolo FL, Di Stefano A, Sabatini F, Folkerts G. Reactive nitrogen species in the respiratory tract. Eur J Pharmacol 2006; 533: 240-252.
89 Tsikas D. Methods of quantitative analysis of the nitric oxide metabolites nitrite and nitrate in human biological fluids. Free Radic Res 2005; 39: 797-815.

90 Marzinzig M, Nussler AK, Stadler J, et al. Improved methods to measure end products of nitric oxide in biological fluids: nitrite, nitrate, and S-nitrosothiols. Nitric Oxide 1997; 1: 177-189.

91 Stratford MR. Measurement of nitrite and nitrate by highperformance ion chromatography. Methods Enzymol 1999; 301: 259-269.

92 Di Matteo V, Esposito E. Methods for the determination of nitrite by high-performance liquid chromatography with electrochemical detection. J Chromatogr A 1997; 789: 213-219.

93 Corradi M, Pesci A, Casana R, et al. Nitrate in exhaled breath condensate of patients with different airway diseases. Nitric Oxide 2003; 8: 26-30.

94 Maziak W, Loukides S, Culpitt S, Sullivan P, Kharitonov SA, Barnes PJ. Exhaled nitric oxide in chronic obstructive pulmonary disease. Am J Respir Crit Care Med 1998; 157: 998-1002.

95 Gaston B, Drazen JM, Loscalzo J, Stamler JS. The biology of nitrogen oxides in the airways. Am J Respir Crit Care Med 1994; 149: 538-551.

96 Ichinose M, Sugiura H, Yamagata S, et al. Xanthine oxidase inhibition reduces reactive nitrogen species production in COPD airways. Eur Respir J 2003; 22: 457-461. 